\title{
Efficacy and Safety of Taspoglutide Versus Sitagliptin for Type 2 Diabetes Mellitus (T-Emerge 4 Trial)
}

Richard M. Bergenstal - Adriana Forti •

Jean-Louis Chiasson $\cdot$ Michael Woloschak •

Mark Boldrin • Raffaella Balena

To view enhanced content go to www.diabetestherapy-open.com

Received: August 9, 2012 / Published online: November 9, 2012

(c) The Author(s) 2012. This article is published with open access at Springerlink.com

\section{ABSTRACT}

Introduction: The efficacy and safety of taspoglutide, a long-acting human glucagonlike peptide-1 analog, were compared with

For the T-emerge 4 Study Group.

Study investigators listed in the Appendix.

ClinicalTrials.gov identifier: NCT00754988.

R. M. Bergenstal ( $\square)$

Park Nicollet International Diabetes Center,

Minneapolis, MN 55416, USA

e-mail: Richard.Bergenstal@ParkNicollet.com

A. Forti

Universidade Federal do Ceará, Fortaleza, Brazil

J.-L. Chiasson

Centre de Recherche, Centre Hospitalier de

l'Université de Montréal, Université de Montréal,

Montreal, QC H2Q 1T8, Canada

M. Woloschak $\cdot$ M. Boldrin

Roche Pharmaceuticals, Nutley, NJ 07110, USA

R. Balena

F. Hoffmann-La Roche AG, 4070 Basel, Switzerland

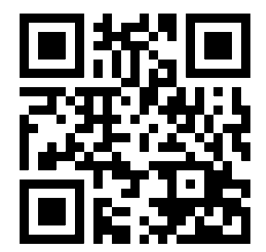

Enhanced content for this article is

available on the journal web site:

www.diabetestherapy-open.com sitagliptin or placebo, as adjunct to metformin, in patients with inadequately controlled type 2 diabetes.

Methods: In this randomized, double-blind, double-dummy, parallel-group trial, patients were randomized to taspoglutide $10 \mathrm{mg}$ once weekly (QW), $20 \mathrm{mg}$ QW, $100 \mathrm{mg}$ sitagliptin once daily (QD), or placebo for 24 weeks, followed by 28-week short-term and 104-week long-term extension periods. The primary endpoint was change in glycosylated hemoglobin $\left(\mathrm{HbA}_{1 \mathrm{c}}\right)$ after 24 weeks.

Results: In this study, 666 patients (baseline $\mathrm{HbA}_{1 \mathrm{c}}, 7.96 \%$ [SD, 0.87]; fasting plasma glucose, $9.61 \mathrm{mmol} / \mathrm{L}$ [2.56]; body weight, $92.4 \mathrm{~kg}$ [19.3]) were randomized to taspoglutide $10 \mathrm{mg}$ QW $\quad(n=190), \quad 20 \mathrm{mg} \quad \mathrm{QW} \quad(n=198)$, $100 \mathrm{mg}$ sitagliptin QD $(n=185)$, or placebo $(n=93)$ for 24 weeks. After 24 weeks, least squares mean (SE) $\mathrm{HbA}_{1 \mathrm{c}}$ reductions were greater with taspoglutide $10 \mathrm{mg} \quad(-1.23 \%$ [0.06]) and $20 \mathrm{mg}(-1.30 \%$ [0.06]) versus sitagliptin $(-0.89 \%[0.06])$ or placebo $(-0.10 \%$ [0.08]). Mean treatment differences with taspoglutide $10 \mathrm{mg}$ and $20 \mathrm{mg}$ were -0.34 (95\% confidence intervals [CI]: $-0.49,-0.19)$ and $-0.41(-0.56,-0.26)$ versus sitagliptin; and 
$-1.13(-1.31,-0.95)$ and $-1.20(-1.38,-1.02)$ versus placebo. Weight loss was greater with taspoglutide $10 \mathrm{mg}(-1.8 \mathrm{~kg}$ [0.3]) and $20 \mathrm{mg}$ $(-2.6 \mathrm{~kg}[0.3])$ than sitagliptin $(-0.9 \mathrm{~kg}$ [0.3]) or placebo $(-0.5 \mathrm{~kg}[0.4])$. Effects on $\mathrm{HbA}_{1 \mathrm{c}}$ and weight loss continued through 52 weeks of treatment. No cases of severe hypoglycemia occurred with any active treatment. Gastrointestinal adverse events, and allergic and injection-site reactions were higher in the taspoglutide groups, causing higher discontinuation rates. Anti-taspoglutide antibodies were confirmed in $46 \%$ of patients.

Conclusion: Taspoglutide demonstrated better efficacy on glycemic control and weight loss than sitagliptin, but a high incidence of adverse events led to high discontinuation rates. The safety profile of taspoglutide in this trial was similar to other trials in the clinical program, and led to the discontinuation of dosing.

Keywords: Dipeptidyl peptidase-4; Glucagonlike peptide-1; Glycemic control; Metformin; Sitagliptin; Taspoglutide; Type 2 diabetes mellitus; Weight loss

\section{INTRODUCTION}

Despite the number of antidiabetes medications currently available, there is still difficulty achieving tight glycemic control in patients with type 2 diabetes [1]. An emerging class of antidiabetes agents, known as incretin-based therapies, enhances or replaces the glucosedependent glucoregulatory effects of incretin hormones, primarily glucagon-like peptide-1 (GLP-1) [2]. Native GLP-1 regulates the postprandial rise in blood glucose by augmenting insulin release and blunting glucagon secretion, delaying gastric emptying, and improving satiety. These effects are shortlived, as the active hormone is rapidly degraded by the enzyme dipeptidyl peptidase-4 (DPP-4). To take advantage of the incretin system, two types of incretin-based therapies (GLP-1 receptor agonists and DPP-4 inhibitors) have been developed and have been shown to improve fasting and postprandial glucose control with minimal hypoglycemia, and to induce weight loss to varying extents based on their relative stimulation of incretin activity $[3,4]$.

Currently, there are two GLP-1 receptor agonists (liraglutide and exenatide) available for treating type 2 diabetes. Liraglutide, administered as a once-daily (QD) injection, has demonstrated to be effective in improving glycemic control, with a lower risk of hypoglycemia, and appreciable weight loss $[5,6]$. Exenatide, available for administration as a twice-daily injection and in some countries as a once-weekly (QW) injection, results in improved glycemic control, without hypoglycemia, and significant weight loss [7, 8]. The most common treatment-emergent adverse events (AEs) observed with GLP-1 receptor agonists are related to gastrointestinal AEs (nausea, vomiting, diarrhea, and upper abdominal pain). These AEs are considered dose-related and typically become less frequent with subsequent dosing over time. Several DPP-4 inhibitors are approved, including sitagliptin, saxagliptin, and linagliptin. These QD agents have the advantage of being oral medications, but offer modest glycemic efficacy and have little effect on body weight [9-11].

Taspoglutide, a human GLP-1 analog, elicits a long-lasting incretin effect through its enhanced enzymatic stability and sustained-release formulation, allowing for QW administration [12]. In phase 2 trials, taspoglutide $\mathrm{QW}$ versus placebo in combination with metformin favorably lowered blood glucose and body 
weight, and was well tolerated [13, 14]. The present study (T-emerge 4) was designed to compare the efficacy and safety of taspoglutide versus sitagliptin or placebo over 24 weeks in patients with type 2 diabetes inadequately controlled with metformin alone. A short-term extension phase of 28 weeks followed by a longterm extension phase of 52 weeks were planned to follow the core phase of the study to evaluate long-term effects of taspoglutide compared with sitagliptin. The trial was terminated on January 11, 2011 during the long-term extension phase owing to the discontinuation of dosing in the phase 3 trials because of higher than expected rates of study withdrawals of taspoglutidetreated patients. Here, the authors present key efficacy results from the 24-week core phase and 28-week short-term extension phase, and full safety data for the entire study up to the last dose administered.

\section{MATERIALS AND METHODS}

\section{Study Design and Interventions}

This phase 3 study was a randomized, doubleblind, double-dummy, placebo-, and activecontrolled four-arm parallel trial undertaken at
149 clinical sites in 23 countries. Patients were randomized to one of the four following treatment groups in a 2:2:2:1 ratio: (1) taspoglutide $10 \mathrm{mg}$ subcutaneously (s.c.) QW plus oral placebo-sitagliptin QD; (2) taspoglutide $20 \mathrm{mg}$ s.c. QW (after $10 \mathrm{mg}$ s.c. for the first 4 weeks) plus oral placebo-sitagliptin QD; (3) sitagliptin $100 \mathrm{mg}$ orally QD plus placebo-taspoglutide s.c. QW; or (4) placebositagliptin orally QD plus placebo-taspoglutide s.c. QW All patients were instructed to maintain their metformin treatment at a stable dose $(\geq 1,500 \mathrm{mg} /$ day as documented at screening) throughout the study period, as well as their diet and exercise habits.

All patients participated in the initial 24-week, double-blind, placebo-, and active-controlled core phase (phase A) of the study (Fig. 1). This was followed by a 28-week, single-blind, activetreatment period (extension phase B) during which patients in group 4 (double placebo group) were switched either to taspoglutide $10 \mathrm{mg}$ or taspoglutide $20 \mathrm{mg}$ s.c. QW (after $10 \mathrm{mg}$ s.c. for the first 4 weeks) plus placebositagliptin orally QD Finally, only those patients randomized at study initiation to the taspoglutide or sitagliptin groups were maintained in a doubleblind, active-controlled period and followed for

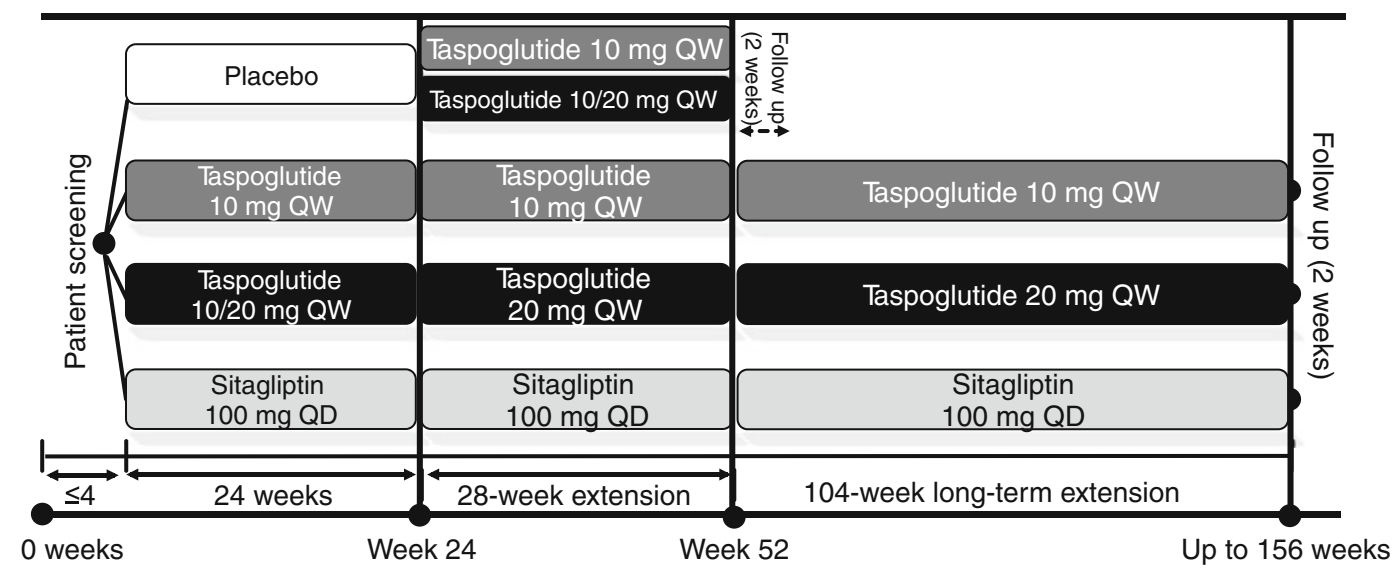

Fig. 1 Study design. Patients randomized to taspoglutide $20 \mathrm{mg}$ QW received taspoglutide $10 \mathrm{mg}$ QW for 4 weeks followed by the $20 \mathrm{mg} \mathrm{QW}$. $Q D$ once daily, $Q W$ once weekly 
up to an additional 104 weeks; this was the longterm extension phase. Patients originally randomized to the double placebo group did not participate in the long-term extension phase.

\section{Study Participants}

Eligible participants were aged $18-75$ years with type 2 diabetes, and had inadequate glycemic control (glycosylated hemoglobin [ $\left.\mathrm{HbA}_{1 \mathrm{c}}\right]$ $\geq 7.0 \%$ to $\leq 10.0 \%$ at screening), a body mass index (BMI) $\geq 25 \mathrm{~kg} / \mathrm{m}^{2}$ (>23 for Asians) to $\leq 45 \mathrm{~kg} / \mathrm{m}^{2}$ (and stable within $\pm 5 \%$ for $\geq 12$ weeks), and were receiving metformin (stable dose $\geq 1,500 \mathrm{mg} /$ day or maximally tolerated dose for $\geq 12$ weeks before screening). Participants were excluded if they had chronic diabetic complications (diabetic nephropathy, neuropathy, and retinopathy), gastrointestinal disease, previous bariatric surgery, pancreatitis, cardiovascular disease, or previous exposure to other oral antihyperglycemic or weightlowering drugs within 12 weeks, $>1$ week of insulin within 6 months, or another GLP-1 mimetic or analog at any time.

The trial was conducted in accordance with the Declaration of Helsinki and national regulations, and the protocol was approved by local independent ethics committees or institutional review boards. All participants provided written consent prior to any procedure.

\section{Randomization and Masking}

Randomization was stratified by baseline $\mathrm{HbA}_{1 \mathrm{c}}$ $(<8.0 \%$ or $\geq 8.0 \%)$ to prevent imbalances in the treatment arms. Randomization was performed centrally using either a telephone- or web-based system, and patient randomization numbers were generated by the sponsor. Investigators were masked to the results of efficacy assessments during the study, and the sponsor medical review of data avoided systematic unblinding of the treatment code.

\section{Study Endpoints}

The primary efficacy endpoint was absolute change in $\mathrm{HbA}_{1 \mathrm{c}}$ (\%) from baseline to 24 weeks of treatment. The secondary efficacy endpoints included changes in $\mathrm{HbA}_{1 \mathrm{c}}$, percentage of patients achieving $\mathrm{HbA}_{1 \mathrm{c}} \leq 6.5 \%$ and $\leq 7 \%$, fasting plasma glucose, and body weight at 24 and 52 weeks of treatment, as well as changes in beta-cell function (fasting proinsulin, fasting insulin, fasting proinsulin:insulin ratio, homeostatic model assessment [HOMA]-B), and lipid profile after 52 weeks of treatment. An additional exploratory efficacy endpoint included change in blood pressure after 52 weeks of treatment.

Tolerability/safety assessments included documenting any treatment-emergent AEs or abnormalities in vital signs and physical examination findings, clinical laboratory tests (hematology, biochemistry, and urinalysis), electrocardiogram, or the development of antitaspoglutide antibodies. Documented hypoglycemia was defined as any episode with or without typical symptoms accompanied by measured plasma-equivalent glucose concentration $\quad<3.9 \mathrm{mmol} / \mathrm{L}$. Confirmed (symptomatic or asymptomatic) hypoglycemia was defined by a plasma-equivalent glucose measurement of $\leq 3.1 \mathrm{mmol} / \mathrm{L}$. Severe hypoglycemia was defined as an event requiring assistance of another to administer carbohydrate, glucagon, or other resuscitative actions. Also considered was the need for rescue medications for glycemic control during the study. The following criteria were used to determine the need for rescue medication: if fasting plasma glucose $>13.3 \mathrm{mmol} / \mathrm{L}$ from 
week $4-8,>12.2 \mathrm{mmol} / \mathrm{L}$ from week $8-12$, and $>11.1 \mathrm{mmol} / \mathrm{L}$ from week $12-24$, and if $\mathrm{HbA}_{1 \mathrm{c}}$ $>8 \%$ between weeks 24-52, $\mathrm{HbA}_{1 \mathrm{c}}>7.5 \%$ between weeks 52-104, and $\mathrm{HbA}_{1 \mathrm{c}}>7 \%$ between weeks 104-156. During the longterm extension phase of the study, a risk mitigation plan was implemented requiring discontinuation of patients with confirmed positive anti-taspoglutide antibody test $\geq 230 \mathrm{ng}$-eq $/ \mathrm{mL}$, regardless of the presence or absence of allergic AEs and discontinuation of patients with treatment-related systemic allergic reactions.

\section{Statistical Analysis}

It was calculated that 630 patients would have to be randomized (180 in the three active treatment groups and 90 in the placebo group). This provided $90 \%$ power with a twosided alpha of 0.05 to detect a difference of $0.6 \%$ (SD 1.2\%) in change in $\mathrm{HbA}_{1 \mathrm{c}}$ from baseline to 24 weeks for taspoglutide versus placebo (first primary objective), and an $80 \%$ power to detect a difference of $0.1 \%$ for taspoglutide versus sitagliptin (second primary objective).

Analyses of efficacy endpoints were based on the intent-to-treat population, consisting of all randomized patients who received at least one dose of study drug, and had a baseline and one or more postbaseline evaluable measurements of $\mathrm{HbA}_{1 \mathrm{c}}$. The safety analysis was based on the safety population that included all patients who received $\geq 1$ dose of study drug and had at least one safety follow-up (or reported any AEs).

Analysis of variance was used to assess the primary endpoint (absolute change in $\mathrm{HbA}_{1 \mathrm{c}}$ ) with treatment and region as variables, and baseline $\mathrm{HbA}_{1 \mathrm{c}}$ value as covariate. Missing values were imputed as the last observation carried forward. For testing of taspoglutide versus placebo and sitagliptin, a fixed sequential test procedure was used to control multiplicity across endpoints. $\mathrm{HbA}_{1 \mathrm{c}}$ was tested for significance first, then other secondary endpoints sequentially (starting with fasting plasma glucose and body weight). If significant, the testing continued, but if not, the testing stopped. The Hochberg procedure also was applied to control for multiple comparisons across treatment groups (in $\mathrm{HbA}_{1 \mathrm{c}}$ and other endpoints, if applicable). Analysis of continuous variance was used for the other continuous secondary and exploratory endpoints (but was not part of the testing sequence). The Clopper-Pearson method was used to calculate the $\mathrm{HbA}_{1 \mathrm{c}}$ and body weight response rates as well as related 95\% confidence intervals (CI).

\section{RESULTS}

Overall, 666 patients were randomized and 656 (98\%) qualified for the safety population (i.e., received at least one dose of study medication and had at least one safety assessment). Of those randomized, $542(81 \%)$ patients completed the 24-week core phase and 437 (66\%) patients completed the 28-week short-term extension phase (Fig. 2). During the core phase, premature discontinuation occurred in $21 \%, 28 \%, 7 \%$, and $11 \%$ of patients receiving taspoglutide $10 \mathrm{mg}$, taspoglutide $20 \mathrm{mg}$, sitagliptin $100 \mathrm{mg}$, or placebo, respectively, most frequently resulting from AEs. Across the core phase and short-term extension phase, the greatest number of patients withdrew in the taspoglutide $10 \mathrm{mg}$ (36\%) and taspoglutide $20 \mathrm{mg}$ (51\%) groups compared with the other groups (placebo/taspoglutide $10 \mathrm{mg}$ [14\%], placebo/taspoglutide $20 \mathrm{mg}$ [26\%], and sitagliptin $100 \mathrm{mg}$ [14\%]). No major differences were seen between treatment groups for baseline 


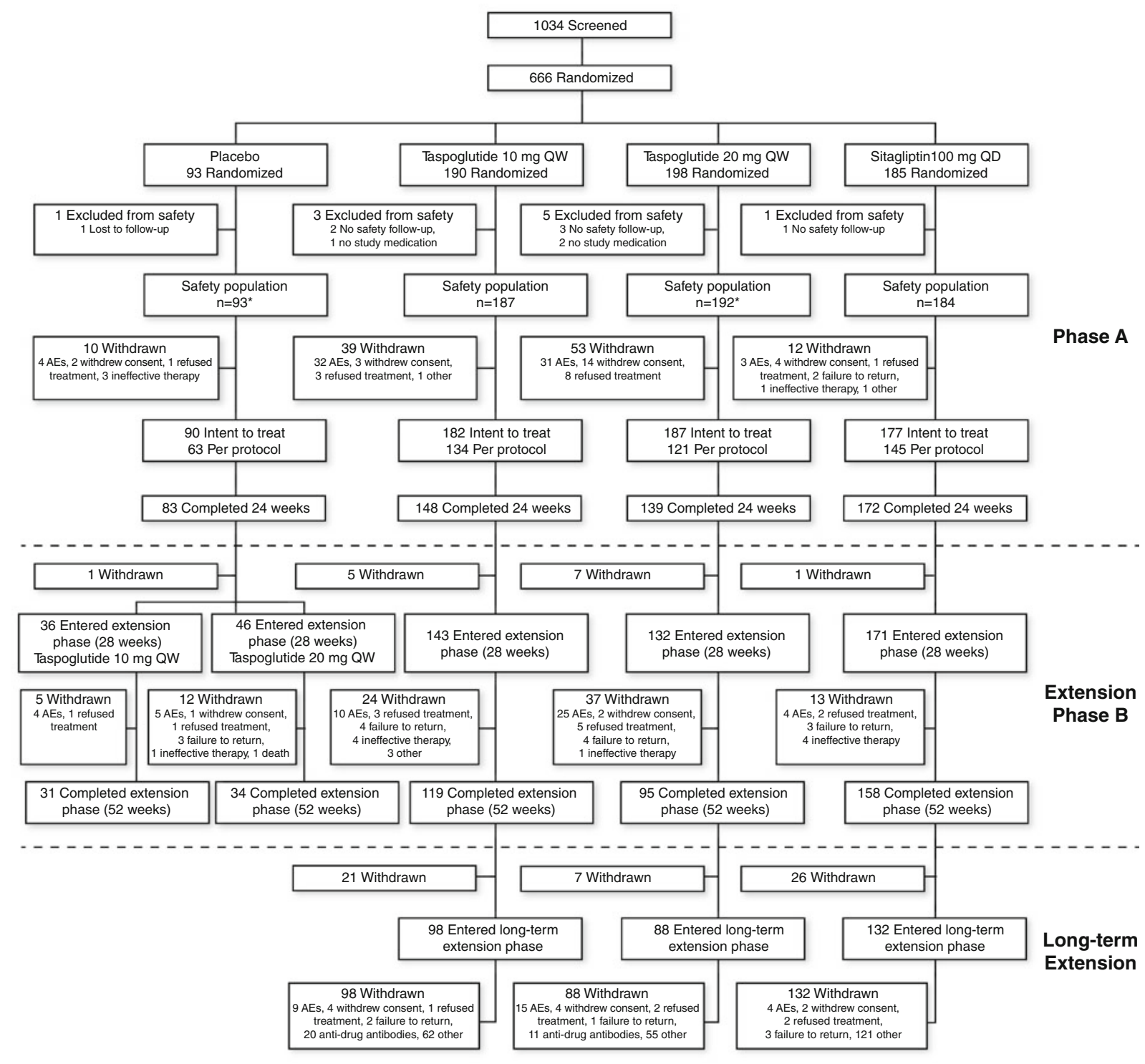

Fig. 2 Patient allocation. $A E$ adverse event, $Q D$ once daily, $Q W$ once weekly. *One patient randomized to the taspoglutide $20 \mathrm{mg}$ group received placebo for the first
4 weeks of the study and was considered in the placebo group for the safety population

sitagliptin (Fig. 3a). Mean $\mathrm{HbA}_{1 \mathrm{c}}$ reductions at week 24 were $-1.23 \%$ (SE 0.06), $-1.30 \%$ (0.06), and $-0.89 \%$ (0.06) for taspoglutide 10 and $20 \mathrm{mg}$, and sitagliptin $100 \mathrm{mg}$, respectively, versus $-0.1 \%$ (0.8) for placebo (Fig. 3b). Mean treatment differences were $-0.34 \quad(95 \% \mathrm{CI}$ $-0.49,-0.19)$ and $-0.41 \quad(95 \%$ CI -0.56 , -0.26 ) for taspoglutide $10 \mathrm{mg}$ and $20 \mathrm{mg}$ versus sitagliptin (both $P<0.001$ ), and -1.13 
Table 1 Baseline demographic and clinical characteristics (intent-to-treat population, $n=636$ )

\begin{tabular}{|c|c|c|c|c|}
\hline & $\begin{array}{l}\text { Placebo } \\
(n=90)\end{array}$ & $\begin{array}{l}\text { Taspoglutide } \\
10 \mathrm{mg}(n=182)\end{array}$ & $\begin{array}{l}\text { Taspoglutide } \\
20 \mathrm{mg}(n=187)\end{array}$ & $\begin{array}{l}\text { Sitagliptin } \\
100 \mathrm{mg}(n=177)\end{array}$ \\
\hline \multicolumn{5}{|l|}{ Sex } \\
\hline Male & $47(52)$ & $102(56)$ & $98(52)$ & $105(59)$ \\
\hline Female & $43(48)$ & $80(44)$ & $89(48)$ & $72(41)$ \\
\hline Age, mean (SD), years & $56.1(10.1)$ & $55.3(9.5)$ & $56.8(8.8)$ & $55.5(9.9)$ \\
\hline \multicolumn{5}{|l|}{ Race } \\
\hline White & $69(77)$ & $143(79)$ & $153(82)$ & $135(76)$ \\
\hline Asian & $9(10)$ & $15(8)$ & $14(7)$ & $19(11)$ \\
\hline Black & $5(6)$ & $13(7)$ & $8(4)$ & $10(6)$ \\
\hline Other & $7(8)$ & $11(6)$ & $12(6)$ & $13(7)$ \\
\hline \multicolumn{5}{|l|}{ Ethnicity } \\
\hline Non-Hispanic & $80(89)$ & $150(82)$ & $152(81)$ & $148(84)$ \\
\hline Hispanic & $10(11)$ & $32(18)$ & $35(19)$ & $29(16)$ \\
\hline Weight, mean (SD), kg & $91.1(19.0)$ & $93.6(20.4)$ & $91.8(18.0)$ & $92.5(19.7)$ \\
\hline Body mass index, mean $(\mathrm{SD}), \mathrm{kg} / \mathrm{m}^{2}$ & $32.5(5.5)$ & $32.7(5.2)$ & $32.3(5.0)$ & $32.4(5.0)$ \\
\hline $\mathrm{HbA}_{1 \mathrm{c}}$, mean (SD), \% & $8.03(0.83)$ & $7.95(0.93)$ & $7.97(0.86)$ & $7.94(0.85)$ \\
\hline \multicolumn{5}{|l|}{$\mathrm{HbA}_{1 \mathrm{c}}$ baseline category } \\
\hline$<8.0 \%$ & $46(51)$ & $103(57)$ & $106(57)$ & $100(56)$ \\
\hline$\geq 8.0 \%$ & $44(49)$ & $79(43)$ & $81(43)$ & $77(44)$ \\
\hline Fasting plasma glucose, mean $(\mathrm{SD}), \mathrm{mmol} / \mathrm{L}$ & $9.66(2.60)$ & $9.74(2.48)$ & $9.64(2.68)$ & $9.40(2.50)$ \\
\hline Duration of diabetes, mean (SD), years & $5.5(3.9)$ & $6.1(4.8)$ & $5.7(4.7)$ & $6.0(5.0)$ \\
\hline
\end{tabular}

Data are $n$ (\%) unless otherwise indicated

$H b A_{\text {Ic }}$ glycosylated hemoglobin

(95\% CI $-1.31,-0.95)$ and $-1.20(95 \%$ CI $-1.38,-1.02$ ) for taspoglutide 10 and $20 \mathrm{mg}$ versus placebo (both $P<0.001$ ). At 52 weeks, these reductions were still significant with a mean change in $\mathrm{HbA}_{1 \mathrm{c}}$ of -1.03 (95\% CI -1.15 , $-0.91),-1.18$ (95\% CI $-1.30,-1.06)$, and $-0.66(95 \%$ CI $-0.78,-0.54)$ for taspoglutide $10 \mathrm{mg}$, taspoglutide $20 \mathrm{mg}$, and sitagliptin $100 \mathrm{mg}$, respectively. After 52 weeks of treatment, a greater proportion of patients achieved $\mathrm{HbA}_{1 \mathrm{c}}$ targets of $\leq 6.5 \%$ or $\leq 7.0 \%$ with taspoglutide 10 and $20 \mathrm{mg}$ than with sitagliptin $\left(\mathrm{HbA}_{1 \mathrm{c}} \leq 6.5 \%: 37.9 \%\right.$ and $41.2 \%$ vs. 17.5\%, respectively; $\mathrm{HbA}_{1 \mathrm{c}} \leq 7.0 \%: 57.7 \%$ and $67.9 \%$ vs. $47.5 \%)$.

At 24 weeks, both doses of taspoglutide achieved significantly greater reductions in fasting plasma glucose than sitagliptin or placebo (Fig. 4a). The mean reductions from baseline in fasting plasma glucose were $-2.16 \mathrm{mmol} / \mathrm{L} \quad$ (SE 0.14), $\quad-2.34 \mathrm{mmol} / \mathrm{L}$ (SE 0.14), $\quad-1.35 \mathrm{mmol} / \mathrm{L} \quad$ (SE 0.14), and $-0.07 \mathrm{mmol} / \mathrm{L}$ (SE 0.20) for taspoglutide $10 \mathrm{mg}$, taspoglutide $20 \mathrm{mg}$, sitagliptin $100 \mathrm{mg}$, 

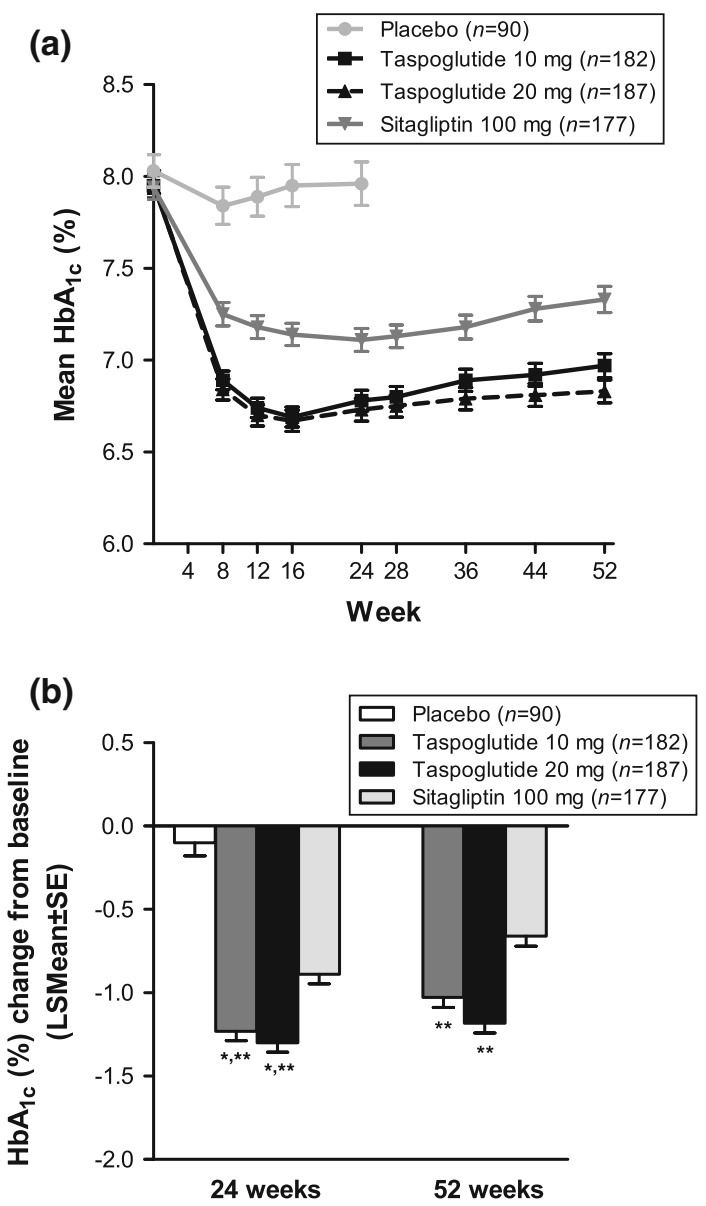

Fig. 3 Effects of treatments on $\mathrm{HbA}_{1 \mathrm{c}}$. a Changes in $\mathrm{HbA}_{1 \mathrm{c}}(\%)$ during 52 weeks of treatment. b Changes in $\mathrm{HbA}_{1 \mathrm{c}}$ (\%) from baseline after 24 and 52 weeks of treatment. $H b A_{1 c}$ glycosylated hemoglobin, LSMean least squares mean. ${ }^{*} P<0.001$ vs. placebo, ${ }^{* *} P<0.001$ vs. sitagliptin

and placebo, respectively (Fig. 4b). Mean treatment differences were $-0.81 \mathrm{mmol} / \mathrm{L}$ $(95 \%$ CI $-1.19,-0.43)$ and $-0.98 \mathrm{mmol} / \mathrm{L}$ (95\% CI $-1.36,-0.61)$ for taspoglutide $10 \mathrm{mg}$ and $20 \mathrm{mg}$ versus sitagliptin (both $P<0.001$ ), and $-2.09 \mathrm{mmol} / \mathrm{L}(95 \% \mathrm{CI}-2.55,-1.62)$ and $-2.26 \mathrm{mmol} / \mathrm{L} \quad(95 \% \quad \mathrm{CI}-2.72,-1.80)$ for taspoglutide 10 and $20 \mathrm{mg}$ versus placebo (both $P<0.001$ ). Reductions persisted at 52 weeks with fasting plasma glucose mean changes from baseline of $-1.75 \mathrm{mmol} / \mathrm{L}$ (95\% CI $-2.05,-1.45),-2.05 \mathrm{mmol} / \mathrm{L}$ (95\% (a)
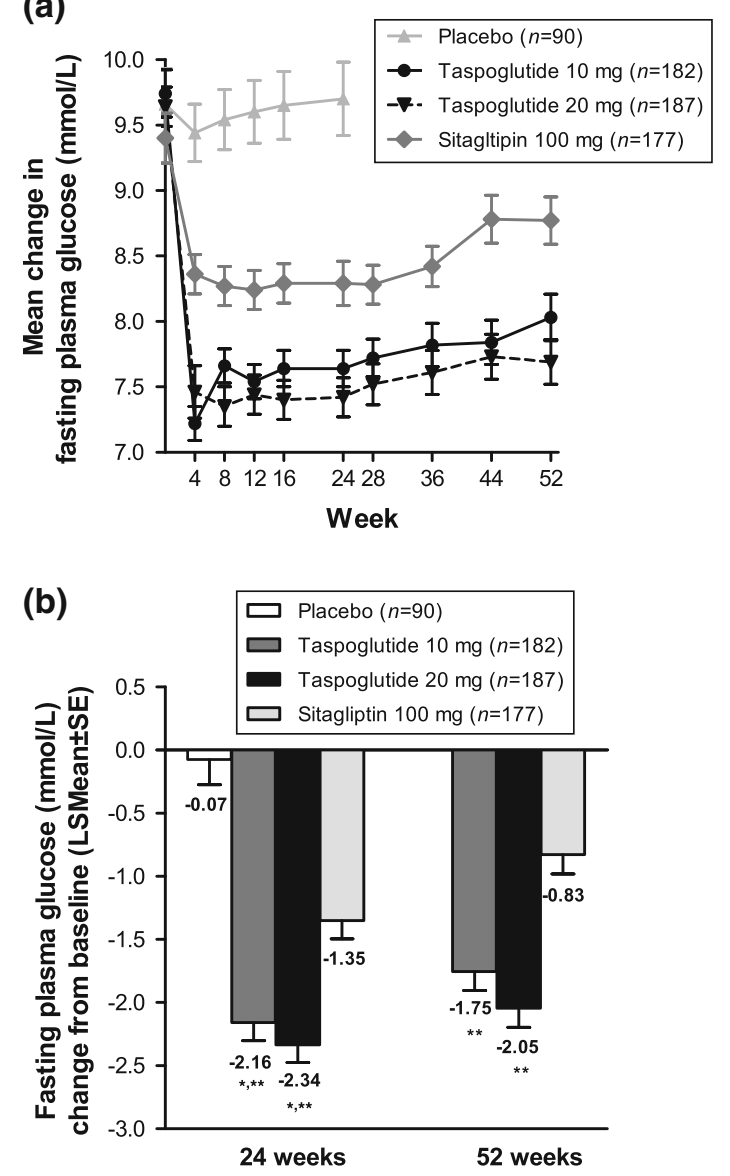

Fig. 4 Effects of treatments on fasting plasma glucose. a Changes in fasting plasma glucose $(\mathrm{mmol} / \mathrm{L})$ during 52 weeks of treatment. b Changes in fasting plasma glucose $(\mathrm{mmol} / \mathrm{L})$ from baseline after 24 and 52 weeks of treatment. LSMean least squares mean. ${ }^{*} P<0.001$ vs. placebo, ${ }^{* *} P<0.001$ vs. sitagliptin

CI $-2.34,-1.75)$, and $-0.83 \mathrm{mmol} / \mathrm{L}(95 \% \mathrm{CI}$ $-1.13,-0.52)$ for taspoglutide $10 \mathrm{mg}$, taspoglutide $20 \mathrm{mg}$, and sitagliptin $100 \mathrm{mg}$, respectively. During the 24 -week core study phase, a higher percentage of patients treated with placebo $(16.7 \%)$ required rescue medication than those treated with taspoglutide 10 and $20 \mathrm{mg}$ (3.8\% and $1.6 \%$, respectively), and sitagliptin (5.1\%). Among those patients receiving treatment for 52 weeks, a lower percentage of patients required rescue medication in the taspoglutide 
10 and $20 \mathrm{mg}$ groups $(11.5 \%$ and $6.4 \%$, respectively) than in the sitagliptin group (18.6\%).

Taspoglutide produced greater reductions in mean body weight than those observed for sitagliptin or placebo (Fig. 5a): $-1.8 \mathrm{~kg}$ (SE 0.3), $-2.6 \mathrm{~kg}$ (SE 0.3), $-0.9 \mathrm{~kg}$ (SE 0.3), and $-0.5 \mathrm{~kg}$ (SE 0.4) for taspoglutide $10 \mathrm{mg}$, taspoglutide $20 \mathrm{mg}$, sitagliptin $100 \mathrm{mg}$, and placebo, respectively (Fig. 5b). At 52 weeks, the following reductions were similar to those observed at 24 weeks: $-1.6 \mathrm{~kg}$ (SE 0.3), $-2.4 \mathrm{~kg}$ (SE 0.3), and $-0.5 \mathrm{~kg}$ (SE 0.3) for taspoglutide $10 \mathrm{mg}$, taspoglutide $20 \mathrm{mg}$, and sitagliptin $100 \mathrm{mg}$, respectively.

Improvements in HOMA-B were observed at 24 weeks with taspoglutide 10 and $20 \mathrm{mg}$ (23.5\% [95\% CI 17.54, 29.53] and 32.1\% [95\% CI 26.11, 38.04], respectively) versus placebo (-3.2\% [95\% CI $-11.67,5.26]$; both $P<0.001)$ and versus sitagliptin (10.3\% [95\% CI 4.14, 16.42]; taspoglutide $10 \mathrm{mg}, \quad P<0.005$ and $20 \mathrm{mg}, \quad P<0.001)$. At 52 weeks, taspoglutide $10 \mathrm{mg}$ and $20 \mathrm{mg}$ significantly increased HOMA-B by $21.8 \%$ (95\% CI $14.27,29.34$; $P<0.05)$ and $31.3 \%$ (95\% CI 23.80, 38.88; $P<0.001)$, respectively, versus sitagliptin by $10.2 \% \quad(95 \%$ CI $2.40,17.91) \quad$ (Table 4 of Appendix). Proinsulin and proinsulin:insulin ratio results, as well as results related to cardiovascular outcomes, are presented in the online Tables 4 and 5 in the Appendix.

\section{Safety and Tolerability}

A majority of patients receiving taspoglutide or sitagliptin experienced at least one AE during the entire study period with most being reported as mild-to-moderate in intensity (Table 2). The most common AEs observed in the taspoglutide $10 \mathrm{mg}$, taspoglutide $20 \mathrm{mg}$, and sitagliptin groups, respectively, were
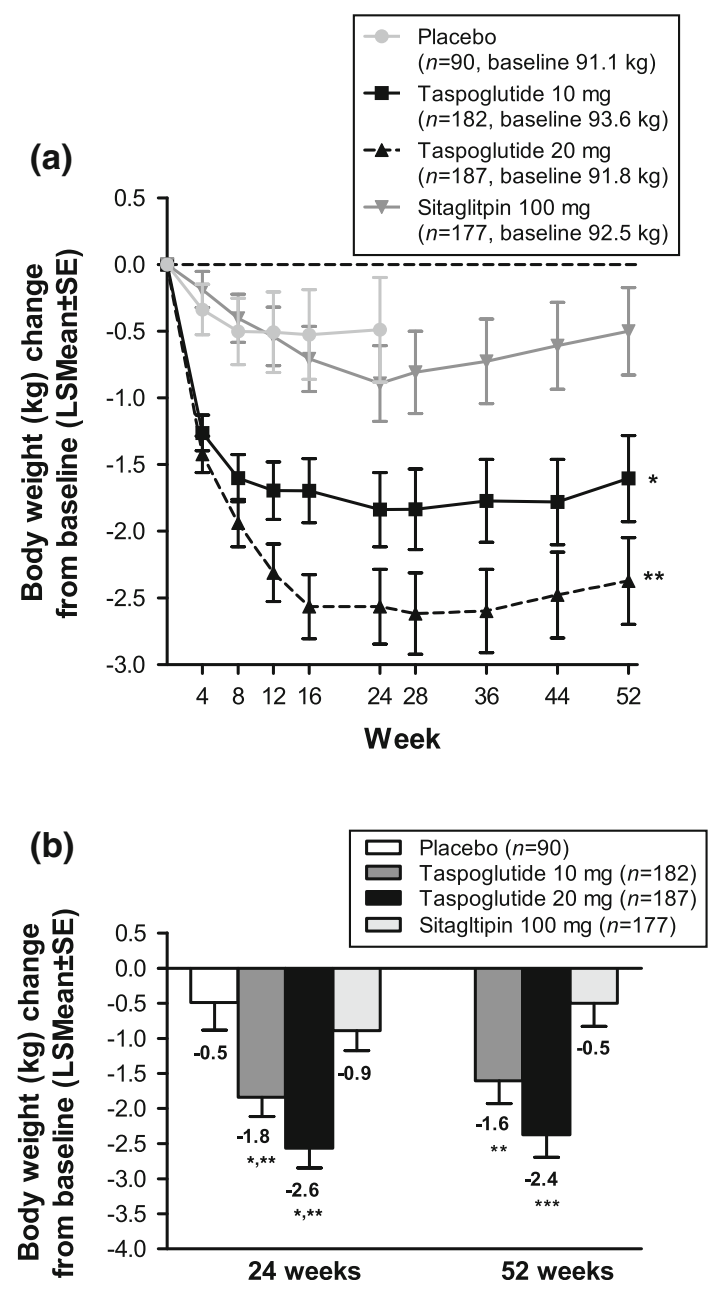

Fig. 5 Effects of treatments on body weight. a Changes in body weight $(\mathrm{kg})$ from baseline over 52 weeks of treatment. LSMean least squares mean. ${ }^{*} P<0.05$ vs. sitagliptin, ${ }^{* *} P<0.001$ vs. sitagliptin. b Changes in body weight $(\mathrm{kg})$ from baseline after 24 and 52 weeks of treatment. ${ }^{*} P<0.01$ vs. placebo, ${ }^{* *} P<0.05$ vs. sitagliptin, ${ }^{* * *} P<0.001$ vs. sitagliptin

nausea $(51.3 \%, 57.8 \%, \quad 17.4 \%)$, vomiting (29.4\%, 40.1\%, 6.5\%), diarrhea $(17.1 \%, 15.1 \%$, $5.4 \%)$, injection-site nodule $(7.5 \%, 17.2 \%$, $1.6 \%)$, injection-site pruritus $(7.0 \%, 17.2 \%$, $2.2 \%)$, injection-site erythema $(6.4 \%, 13.5 \%$, $1.6 \%)$, nasopharyngitis $(7.5 \%, 7.8 \%, 15.2 \%)$, and upper respiratory tract infection $(2.1 \%$, $5.7 \%, 10.3 \%)$. Upper abdominal pain was more common with sitagliptin than with taspoglutide, occurring in $5.4 \%$ of subjects 
Table 2 Summary of adverse events and withdrawals during the entire study period (up to 156 weeks)

\begin{tabular}{|c|c|c|c|}
\hline & $\begin{array}{l}\text { Taspoglutide } \\
10 \mathrm{mg}(n=187)\end{array}$ & $\begin{array}{l}\text { Taspoglutide } \\
20 \mathrm{mg}(n=192)\end{array}$ & $\begin{array}{l}\text { Sitagliptin } \\
100 \mathrm{mg}(n=184)\end{array}$ \\
\hline Patients with at least one $\mathrm{AE}$ & $160(85.6)$ & $183(95.3)$ & $149(81.0)$ \\
\hline Total number of AEs, $n$ & 737 & 931 & 643 \\
\hline Patients with at least one serious $\mathrm{AE}$ & $18(9.6)$ & $18(9.4)$ & $19(10.3)$ \\
\hline Treatment-related serious AEs, $\%^{\mathrm{a}}$ ( $n / n$ serious AEs) & $11(2 / 18)$ & $19(5 / 27)$ & $0(0 / 22)$ \\
\hline Death & $1(0.5)$ & $0(0.0)$ & $0(0.0)$ \\
\hline \multicolumn{4}{|l|}{ AEs leading to withdrawal in $>1 \%$} \\
\hline Total patients with $\geq 1 \mathrm{AE}$ & $53(28.3)$ & $69(35.9)$ & $13(7.1)$ \\
\hline Serious AEs & $2(1.1)$ & $6(3.1)$ & $2(1.1)$ \\
\hline Gastrointestinal disorders & $34(18.2)$ & $39(20.3)$ & $3(1.6)$ \\
\hline Nausea & $14(7.5)$ & $21(10.9)$ & $0(0)$ \\
\hline Vomiting & $15(8.0)$ & $13(6.8)$ & $1(0.5)$ \\
\hline Diarrhea & $2(1.1)$ & $1(0.5)$ & $0(0.0)$ \\
\hline General disorders and administration-site conditions & $5(2.7)$ & $7(3.6)$ & $1(0.5)$ \\
\hline Hypersensitivity $^{\mathrm{b}}$ & $4(2.1)$ & $8(4.2)$ & $1(0.5)$ \\
\hline \multicolumn{4}{|l|}{ AEs reported by $>5 \%$ of patients } \\
\hline Nausea & $96(51.3)$ & $111(57.8)$ & $32(17.4)$ \\
\hline Vomiting & $55(29.4)$ & $77(40.1)$ & $12(6.5)$ \\
\hline Diarrhea & $32(17.1)$ & $29(15.1)$ & $10(5.4)$ \\
\hline Dyspepsia & $18(9.6)$ & $15(7.8)$ & $4(2.2)$ \\
\hline Constipation & $9(4.8)$ & $15(7.8)$ & $3(1.6)$ \\
\hline Gastroesophageal reflux disease & $11(5.9)$ & $11(5.7)$ & $5(2.7)$ \\
\hline Abdominal pain upper & $4(2.1)$ & $6(3.1)$ & $10(5.4)$ \\
\hline Injection-site nodule & $14(7.5)$ & $33(17.2)$ & $3(1.6)$ \\
\hline Injection-site pruritus & $13(7.0)$ & $33(17.2)$ & $4(2.2)$ \\
\hline Injection-site erythema & $12(6.4)$ & $26(13.5)$ & $3(1.6)$ \\
\hline Injection-site pain & $2(1.1)$ & $7(3.6)$ & $16(8.7)$ \\
\hline Injection-site mass & $7(3.7)$ & $13(6.8)$ & $1(0.5)$ \\
\hline Nasopharyngitis & $14(7.5)$ & $15(7.8)$ & $28(15.2)$ \\
\hline Urinary tract infection & $8(4.3)$ & $15(7.8)$ & $12(6.5)$ \\
\hline Upper respiratory tract infection & $4(2.1)$ & $11(5.7)$ & $19(10.3)$ \\
\hline Influenza & $8(4.3)$ & $10(5.2)$ & $13(7.1)$ \\
\hline Hypoglycemia & $21(11.2)$ & $15(7.8)$ & $18(9.8)$ \\
\hline
\end{tabular}


Table 2 continued

\begin{tabular}{llll}
\hline & $\begin{array}{l}\text { Taspoglutide } \\
\mathbf{1 0 ~} \mathbf{~ m g}(\boldsymbol{n}=\mathbf{1 8 7})\end{array}$ & $\begin{array}{l}\text { Taspoglutide } \\
\mathbf{2 0} \mathbf{~ m g}(\boldsymbol{n}=\mathbf{1 9 2})\end{array}$ & $\begin{array}{l}\text { Sitagliptin } \\
\mathbf{1 0 0} \mathbf{~ m g}(\boldsymbol{n}=\mathbf{1 8 4})\end{array}$ \\
\hline $\begin{array}{l}\text { Decreased appetite } \\
\text { Headache }\end{array}$ & $20(10.7)$ & $23(12.0)$ & $5(2.7)$ \\
Dizziness & $15(8.0)$ & $10(5.2)$ & $11(6.0)$ \\
Hypertension & $11(5.9)$ & $14(7.3)$ & $9(4.9)$ \\
Arthralgia & $5(2.7)$ & $14(7.3)$ & $18(9.8)$ \\
Cough & $7(3.7)$ & $6(3.1)$ & $11(6.0)$ \\
Hypersensitivity ${ }^{\mathrm{b}, \mathrm{c}}$ & $3(1.6)$ & $6(3.1)$ & $10(5.4)$ \\
\hline
\end{tabular}

Data are $n(\%)$ of the safety population unless otherwise indicated $(n=563)$. AEs are reported as system organ class or preferred terms (Medical Dictionary for Regulatory Activities [MedDRA] version 14.0)

AEs adverse events

a Serious AEs related to study treatment: taspoglutide $10 \mathrm{mg}(n=2$ : gastritis and inflammatory bowel); taspoglutide $20 \mathrm{mg}$ $(n=5:$ malaise, head injury and cardiac arrest/lactic acidosis/renal failure acute [in single patient]); and none for sitagliptin

b Hypersensitivity refers to the Preferred Term of MedDRA coding dictionary and refers to systemic allergic reactions

c Systemic hypersensitivity was reported in 16 patients: taspoglutide $10 \mathrm{mg}(n=5)$, taspoglutide $20 \mathrm{mg}(n=10)$, and sitagliptin $(n=1)$

compared with $2.1 \%$ and $3.1 \%$ for taspoglutide $10 \mathrm{mg}$ and taspoglutide $20 \mathrm{mg}$.

Similar proportions of patients in the taspoglutide $\quad 10 \mathrm{mg} \quad(11.2 \% \quad[n=21])$, taspoglutide $20 \mathrm{mg} \quad(7.8 \% \quad[n=15]), \quad$ and sitagliptin $(9.8 \%[n=18])$ groups experienced hypoglycemia. None of these were reported as serious or resulted in treatment discontinuation.

Severe AEs were reported in $7 \%, 10 \%$, and $4 \%$ of patients in the taspoglutide $10 \mathrm{mg}$, taspoglutide $20 \mathrm{mg}$, and sitagliptin groups, respectively. In taspoglutide-treated patients, the most common severe AEs were gastrointestinal (33\%), such as nausea and vomiting as well as injection-site reactions (6\%). The frequency of serious AEs (SAEs) was similar across treatment groups (taspoglutide $10 \mathrm{mg} \quad[9.6 \% \quad(n=18)], \quad$ taspoglutide $20 \mathrm{mg}$ $[9.4 \% \quad(n=18)], \quad$ and sitagliptin $\quad[10.3 \%$ $(n=19)])$. In the taspoglutide groups, seven of the following SAEs were deemed treatmentrelated: two in the taspoglutide $10 \mathrm{mg}$ group, gastritis and inflammatory bowel disease; and five in the taspoglutide $20 \mathrm{mg}$ group, malaise, head injury, and cardiac arrest/lactic acidosis/ renal failure acute (in a single patient). No treatment-related SAEs were observed in the sitagliptin group. One death occurred in the taspoglutide $10 \mathrm{mg}$ group, which was not considered treatment-related, but due to underlying chronic obstructive pulmonary disease.

Withdrawals resulting from AEs were more common among patients receiving taspoglutide compared with sitagliptin. In the taspoglutide groups, the most common AEs leading to withdrawal were nausea, vomiting, hypersensitivity, and injection-site-related AEs. In the taspoglutide groups, $18.2-20.3 \%$ of patients withdrew because of gastrointestinal AEs compared with $1.6 \%$ of those in the 
sitagliptin group. Hypersensitivity reactions accounted for $2.1 \%$ and $4.2 \%$ of withdrawals in patients receiving taspoglutide $10 \mathrm{mg}$ and taspoglutide $20 \mathrm{mg}$, respectively, compared with $0.5 \%$ in patients receiving sitagliptin.

Nearly all systemic allergic reactions observed $(n=23)$ were experienced by patients receiving taspoglutide: eight (4\%), 14 (7\%), and one (1\%) for taspoglutide $10 \mathrm{mg}$, taspoglutide $20 \mathrm{mg}$, and sitagliptin, respectively. Systemic hypersensitivity was the most common of these, reported in five and ten patients in the taspoglutide 10 and $20 \mathrm{mg}$ groups, and in one patient in the sitagliptin group. Most systemic allergic reactions led to treatment discontinuation, but none were considered SAEs.

Positive postbaseline anti-taspoglutide antibody results were reported in 41\% (71/172) and $51 \%(91 / 178)$ of taspoglutide $10 \mathrm{mg}$ and taspoglutide $20 \mathrm{mg}$ patients, respectively (Table 3). As a result of the implemented risk mitigation plan, 30\% (106/350) of patients with a confirmed positive anti-taspoglutide antibody test of $\geq 230 \mathrm{ng}-\mathrm{eq} / \mathrm{mL}$ were discontinued during the long-term extension phase of the study.

Prespecified thyroid-related AEs were reported in four (2\%) patients in the taspoglutide $10 \mathrm{mg}$ group, two (1\%) patients in the taspoglutide $20 \mathrm{mg}$ group, and four (2\%) patients in the sitagliptin group. Goitre was reported in three patients receiving taspoglutide and two patients receiving sitagliptin. Increased blood calcitonin levels were identified in two patients receiving taspoglutide (taspoglutide $10 \mathrm{mg}$, $3.42 \mathrm{pmol} / \mathrm{L}$; taspoglutide $20 \mathrm{mg}$, $3.98 \mathrm{pmol} / \mathrm{L}$ ); however, no thyroid ultrasound or biopsy data were available. A thyroid neoplasm was identified in three patients: one patient receiving taspoglutide $10 \mathrm{mg}$ and two patients receiving sitagliptin. In the patient treated with taspoglutide $10 \mathrm{mg}$, the thyroid neoplasm consisted of multiple nodules with no confirmatory biopsy with onset on day 186 of the study. In the two sitagliptin-treated patients, one had bilateral thyroid nodules too small for biopsy initially observed on day 177 and the other patient underwent a partial thyroidectomy for a Hürthle cell benign tumor observed on day 436. There were no cases of acute or chronic pancreatitis.

\section{DISCUSSION}

This head-to-head comparative study showed that taspoglutide 10 and $20 \mathrm{mg}$ QW improved glycemic control more effectively than sitagliptin and placebo without increased risk of hypoglycemia, and it was associated with significantly greater weight loss over 24 weeks in patients inadequately controlled on metformin. Both doses of taspoglutide achieved similar reductions in $\mathrm{HbA}_{1 \mathrm{c}}$ at 24 weeks of $-1.23 \%$ and $-1.30 \%$ from a baseline of approximately $8.0 \%$. The reduction from baseline in $\mathrm{HbA}_{1 \mathrm{c}}$ with sitagliptin was significantly smaller at $-0.89 \%$. Reductions in $\mathrm{HbA}_{1 \mathrm{c}}$ from baseline in taspoglutide-treated patients were observed as early as week 4 and continued to decrease until weeks 12-16, and were generally maintained at 52 weeks. Likewise, improvements in fasting plasma glucose and body weight were statistically significant compared with sitagliptin at weeks 24 and 52. Thus, taspoglutide treatment not only achieved noninferiority, but more importantly achieved superiority relative to sitagliptin for measures of efficacy. Moreover, a greater percentage of taspoglutide-treated patients achieved $\mathrm{HbA}_{1 \mathrm{c}}$ targets of $\leq 6.5 \%$ or $\leq 7.0 \%$ than those treated with sitagliptin. Despite similar reductions in $\mathrm{HbA}_{1 \mathrm{c}}$ for the two doses of taspoglutide, greater weight loss was seen with the $20 \mathrm{mg}$ dose, suggesting that 
Table 3 Summary of confirmed anti-taspoglutide antibody results (taspoglutide safety population, $n=379$ )

\begin{tabular}{|c|c|c|c|}
\hline & \multicolumn{2}{|l|}{ Taspoglutide } & \multirow[t]{2}{*}{ Pooled $(n=379)$} \\
\hline & $10 \mathrm{mg}(n=187)$ & $20 \mathrm{mg}(n=192)$ & \\
\hline Baseline, $n^{\mathrm{a}}$ & 172 & 173 & 345 \\
\hline Confirmed positive, $n(\%)$ & $0(0)$ & $2(1)$ & $2(1)$ \\
\hline Week 24, $n$ & 157 & 166 & 323 \\
\hline Confirmed positive, $n(\%)$ & $43(27)$ & $64(39)$ & $107(33)$ \\
\hline Week $52, n$ & 128 & 116 & 244 \\
\hline Confirmed positive, $n(\%)$ & $48(38)$ & $55(47)$ & $103(42)$ \\
\hline Week $64, n$ & 74 & 62 & 136 \\
\hline Confirmed positive, $n(\%)$ & $20(27)$ & $20(32)$ & $40(29)$ \\
\hline Week $76, n$ & 78 & 66 & 144 \\
\hline Confirmed positive, $n(\%)$ & $0(0)$ & $1(2)$ & $1(1)$ \\
\hline Week $88, n$ & 33 & 29 & 62 \\
\hline Confirmed positive, $n(\%)$ & $15(45)$ & $11(38)$ & $26(42)$ \\
\hline Week 104, $n$ & 3 & 5 & 8 \\
\hline Confirmed positive, $n(\%)$ & $0(0)$ & $2(40)$ & $2(25)$ \\
\hline Postbaseline, $n$ & 172 & 178 & 350 \\
\hline$\geq 1$ confirmed positive, $n(\%)$ & $71(41)$ & $91(51)$ & $162(46)^{\mathrm{b}}$ \\
\hline
\end{tabular}

All percentages are calculated using " $n$ " from the associated scheduled time as the denominator. If a patient had antibody results from more than 1 day in the scheduled time of baseline, weeks 12,24, 52, and 104, the worst result is summarized. A confirmed (positive) antibody response necessitated additional antibody testing at all subsequent planned study visits until the antibody test result returned to pretreatment values

${ }^{a}$ The number of patients who had at least one antibody test during the time windows for the scheduled time

b Per the implemented risk mitigation plan, 30\% (106/350) of patients with a confirmed positive anti-taspoglutide antibody test of $\geq 230 \mathrm{ng}$-eq $/ \mathrm{mL}$ were discontinued during the long-term extension phase of the study

doses higher than necessary for glycemic control may further reduce body weight.

These results are consistent with other studies of incretin-based therapies in similar populations failing to achieve glycemic control with metformin. In comparative studies, liraglutide QD and exenatide QW achieved greater glycemic efficacy than sitagliptin. Liraglutide achieved $\mathrm{HbA}_{1 \mathrm{c}}$ reductions of $-1.24 \%$ to $-1.50 \%$ versus $-0.90 \%$ with sitagliptin, while exenatide QW achieved $-1.5 \%$ versus $-0.9 \%[8,15]$. In other phase 3 trials, GLP-1 receptor agonists have achieved generally comparable $\mathrm{HbA}_{1 \mathrm{c}}$ reductions, although some variability in the treatment responses may have been due to differences in background therapies and baseline $\mathrm{HbA}_{1 \mathrm{c}}[5,6,8,15-18]$. The efficacy of sitagliptin in recent comparative trials, including the present study, was similar to previous studies with $\mathrm{HbA}_{1 \mathrm{c}}$ improvements of $-0.67 \%$ to $-1.0 \%$ in metformin-treated patients $[9,10]$.

Previous studies have also demonstrated greater effects on weight loss with GLP-1 receptor agonists when compared with 
sitagliptin. Liraglutide QD reduced body weight by 2.86 and $3.38 \mathrm{~kg}$ with 1.2 and $1.8 \mathrm{mg}$ liraglutide, respectively, versus $0.96 \mathrm{~kg}$ for sitagliptin [15]. Exenatide QW achieved a weight loss of $2.3 \mathrm{~kg}$ compared with $0.8 \mathrm{~kg}$ for sitagliptin [8]. In other studies, sitagliptin has demonstrated only minimal reductions in body weight of $0.5-0.7 \mathrm{~kg}[9,10]$.

In general, the overall safety profile of taspoglutide was notably worse than sitagliptin primarily because of gastrointestinal events, systemic allergic reactions, and injection-site reactions. However, there was a higher incidence of nasopharyngitis and upper respiratory tract infections reported with sitagliptin than with taspoglutide. The incidence of overall AEs was higher in the taspoglutide $10 \mathrm{mg}$ (85.6\%) and taspoglutide $20 \mathrm{mg}$ (95.3\%) groups than in the sitagliptin (81.0\%) group. The AEs leading to withdrawal were approximately four-to-five-times higher in the taspoglutide $10 \mathrm{mg}(27.8 \%)$ and taspoglutide $20 \mathrm{mg}$ (35.9\%) groups than in the sitagliptin (7.1\%) group.

The greater frequency of gastrointestinal events, primarily nausea, vomiting, and dyspepsia, observed in patients treated with taspoglutide is consistent with that of other GLP-1 receptor agonists [5, 6, 8, 15-18]. In this study, although the gastrointestinal events were usually mild-to-moderate, $19.3 \%$ of patients in the taspoglutide groups experienced gastrointestinal events that led to withdrawals during the course of the study.

Although systemic allergic reactions to protein-based therapies do occur, the incidence observed with taspoglutide treatment is notably higher than what has been reported with other GLP-1 receptor agonists [19]. The most frequent allergic reactions to occur were hypersensitivity. As a result of the risk mitigation plan implemented during the long-term extension phase of the study, patients with a systemic allergic reaction were discontinued from the study. ${ }^{1}$

Anti-taspoglutide antibodies were confirmed positive in $41 \%$ and $51 \%$ of taspoglutide 10 and $20 \mathrm{mg}$ patients, respectively. Previous studies have shown positive antibody production in patients treated with the other GLP-1 receptor agonists, exenatide and liraglutide [19]. Antibody formation to the respective GLP-1 receptor agonist has been reported in $32 \%$ and $45 \%$ of patients treated with exenatide twice-daily and exenatide QW, respectively [20], and $4-13 \%$ of patients treated with liraglutide q.d [21, 22].

Taspoglutide was associated with high rates of injection-site events, such as erythema, pruritus, and nodules. In two exenatide studies, injectionsite reactions, such as bruising were rarely reported $[7,23]$.

In the present study, hypoglycemia was a rare occurrence and the number of events was generally comparable between taspoglutide and sitagliptin groups. Similar low rates of hypoglycemia have been observed for the other GLP-receptor agonists, exenatide and liraglutide [5, 6, 16-18].

This study provides long-term follow-up beyond the standard 24-week endpoint; however, longer-term evaluations outside of the clinical trial setting are needed to determine durability of the response and clinical benefit in this highly prevalent, chronic disease.

\footnotetext{
1 In September 2010, Roche decided to stop dosing patients in the taspoglutide phase III trials because higher than expected discontinuation rates of taspoglutide-treated patients were observed, mainly due to gastrointestinal intolerability, and as a result of the implementation of the risk-mitigation plan to address serious hypersensitivity reactions. Since this time, Roche has worked on the root cause analysis and on the modified taspoglutide formulations with the input of Ipsen. After further analysis, Roche has now made the decision to stop the development of taspoglutide and to return the product to the originator, Ipsen, which is currently pursuing further investigations.
} 
Limitations of this study should be considered when extrapolating the findings to a population beyond those in this study, such as participants with relatively new-onset diabetes, monotherapy limited to metformin, and majority of participants being non-Hispanic whites. In addition, although patients were advised to maintain pre-study diet and exercise habits, there was a lack of rigor with standardization of patients' diet and exercise regimens during the study, which could have compromised the true weight loss potential of taspoglutide.

In conclusion, the current findings showed that taspoglutide QW has several key advantages over sitagliptin, as adjunct to metformin, including superior glycemic control and increased weight loss without increased risk of hypoglycemia. However, treatment with taspoglutide was associated with substantial rates of gastrointestinal intolerability and allergic reactions, and led to high subsequent rates of discontinuation.

\section{ACKNOWLEDGMENTS}

The authors thank the T-emerge 4 study group, their staff, and clinical trial personnel and subjects for participating in the study. The authors also thank Veronica Asnaghi, MD, from F. Hoffmann-La Roche for assistance with the study design and data research. The study and article processing charges were sponsored by $\mathrm{F}$. Hoffmann-La Roche AG, Basel, Switzerland, including involvement in study design, data collection, data review, and data analysis. The manuscript was prepared by the authors, with contributions from the sponsor. The authors had full access to all of the data in the study and had final responsibility for the content and decision to submit for publication. Editorial assistance in the form of drafting of the manuscript, assembling tables and figures, collating author comments, and copy-editing was provided by Susan M. Kaup, PhD, and Nick Brown, PhD, of Evidence Scientific Solutions, and was funded by F. Hoffmann-La Roche AG. Dr. Bergenstal is the guarantor for this article, and takes responsibility for the integrity of the work as a whole.

Conflict of interest. Dr. Bergenstal has acted as a consultant for and received grants from Abbott Diabetes Care, Amylin, Bayer, BectonDickinson, Boehringer Ingelheim, Calibra, Eli Lilly, Halozyme, Helmsley Trust, Hygieia, Johnson \& Johnson, Medtronic, Novo Nordisk, ResMed, Roche, Sanofi Aventis, and Takeda; has acted as a consultant for Valeritas; and received grants from DexCom, Intracia, Merck and National Institutes of Health (all money paid to institution for consultancies and grants); inherited stock in Merck. Dr. Forti has board membership for Sanofi Aventis, Boeringer Ingelheim, Eli Lilly; has acted as a consultant for Novartis and Novo Nordisk; has received grants and speaker bureaus/ lectureships from Novo Nordisk, Roche, Novartis, Servier, Boeringer Ingelheim, Sanofi Aventis, Eli Lilly, and Merck Sharp \& Dohme (money paid to institution for grants). Dr. Chiasson has no conflicts of interest declared. Dr. Woloschak was an employee of Roche Pharmaceuticals at the time of this study, and is now affiliated with Novartis Pharmaceuticals, Inc. Dr. Boldrin is employed by F. Hoffman-La Roche. Dr. Balena was an employee of F. Hoffmann-La Roche AG at the time of this study, and is now affiliated to Eli Lilly and Company Ltd.

Open Access. This article is distributed under the terms of the Creative Commons Attribution Noncommercial License which permits any noncommercial use, distribution, and reproduction in any medium, provided the original author(s) and the source are credited. 


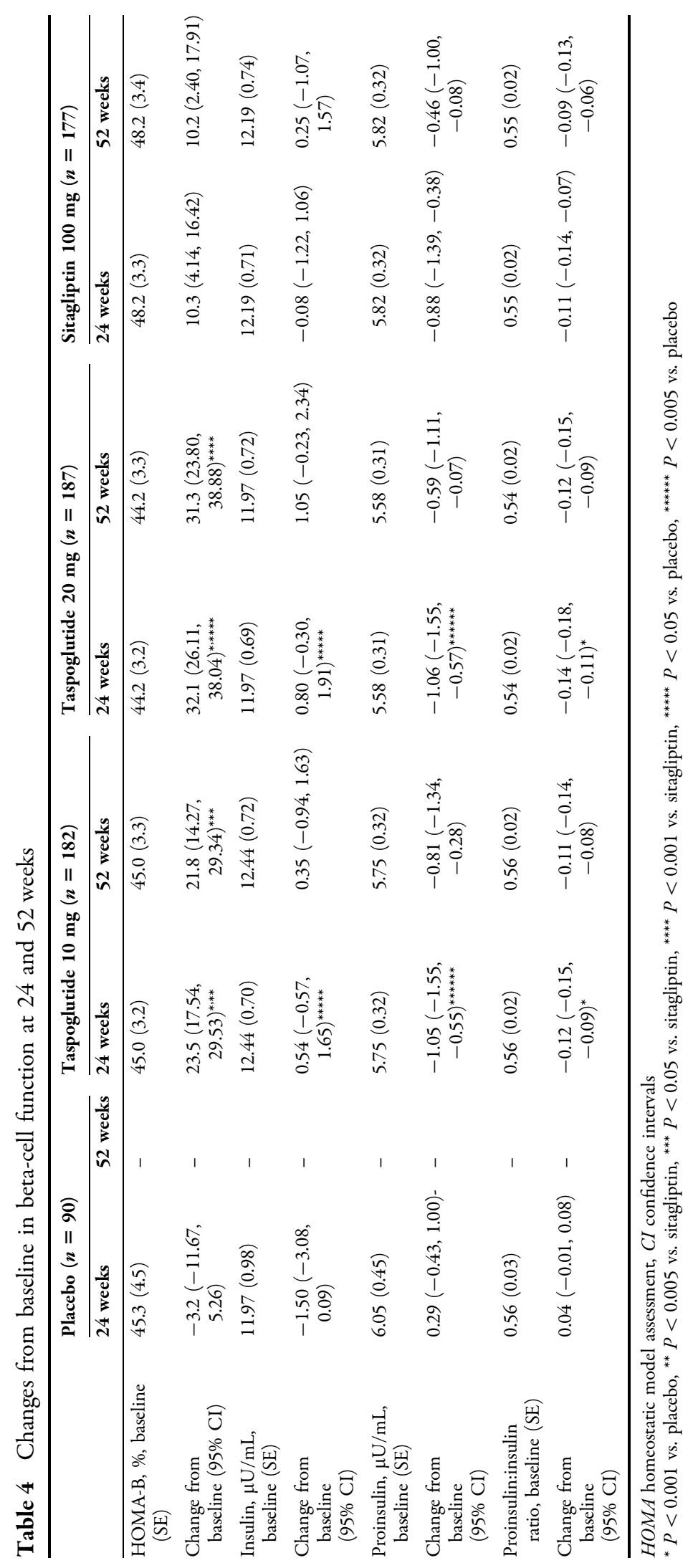




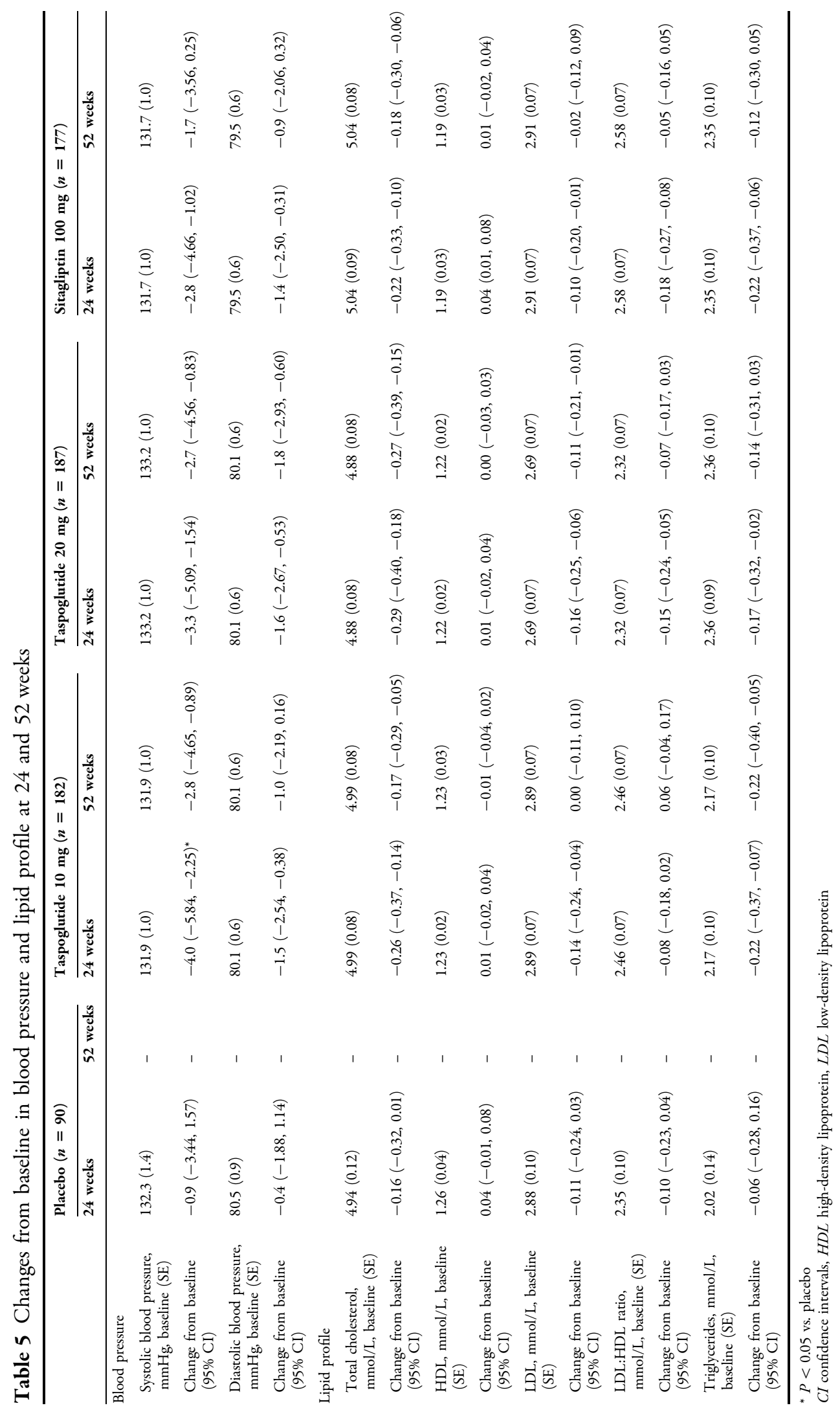




\section{APPENDIX}

See Tables 4 and 5.

Study Investigators. Argentina: A. Alvarisqueta, J. O. Fretes, F. Massari. Australia: T. Davis, G. Wittert. Canada: J.-L. Chiasson, R. Goldenberg, I. Hramiak, B. Lasko. France: B. Bauduceau, B. Cariou, S. Hadjadj, Y. Lorcy, P. Valensi. Germany: U. Aigner, K.-M. Derwahl, E. Frahm, M. Hanefeld, G. R. Meier. Mexico: M. de la Pena, G. Garcia, M. Ibarra, D. Montemayor, J. Rodriguez-Saldana, L. Sauque. Norway: S. Elle, B. Kilhovd, G. Langslet, S. Madsbu, K. Retterstøl. Peru: G. Molina, A. Valdivia. Poland: M. Dabrowski, G. Kania, M. Kozina, G. Laszewska, P. Mader, P. Romanczuk, M. Sroka. Romania: M. Busegeanu, S. Constantinescu, N. Hancu, A. Popescu, M. Vlaiculescu. Slovakia: V. Ambrovicova, J. Duda, A. Gabrisova, M. Macko, J. Vozar. South Africa: G. Ellis, P. Joshi. South Korea: S. H. Baik, D.-J. Kim, K. W. Lee, K. W. Min, S.-J. Yoo. Spain: L. De Teresa, J. C. Ferrer, P. Mezquita, M. Rivas. Sweden: J. Hoffstedt, I. Nordin-Olsson, K.-A. Svensson, B. Strandell. Taiwan: Y.-J. Hung, W.-T. Lu, H.-H. Sheu, C.-Y. Wang. Thailand: R. Leelawattana, S. Suwanwalaikorn. Turkey: I. Satman. UK: J. Litchfield, T. Maxwell, I. McColl, C. Strang, W. Turner. USA: F. Abreu, J. Adler, D. Altamirano, P. Barrington, R. Bergenstal, L. Blair-Britt, S. Canowitz, A. Carr, M. Chen, G. Collins, M. Comianos, G. Cunningham, G. Dailey, M. Davis, J. Downey, H. Ellison, B. Evans, B. Fox, E. Franco, H. Geisberg, W. George, C. Givens, M. Guice, J. Hoekstra, C. Huffman, S. Jones, D. Kendall, M. Khan, B. Lubin, P. Manolukas, J. Martinez, B. McCormick, E. McDermott, J. Miller, A. Mollen, T. Moretto, L. Morris, D. R. Munoz, S. Oates, A. Philis-Tsimikas, R. Pratley, A. Radparvar, K. Roberts, R. D. Rosen, J. Rosenstock, J. Rubino,
J. Saxton, L. Stonesifer, R. L. Topkis, G. Walker, M. Warren, J. Wayne, F. Zieve.

\section{REFERENCES}

1. Krentz AJ, Bailey CJ. Oral antidiabetic agents: current role in type 2 diabetes mellitus. Drugs. 2005;65:385-411.

2. Aaboe K, Krarup T, Madsbad S, Holst JJ. GLP-1: physiological effects and potential therapeutic applications. Diabetes Obes Metab. 2008;10: 994-1003.

3. Deacon CF. Incretin-based treatment of type 2 diabetes: glucagon-like peptide-1 receptor agonists and dipeptidyl peptidase- 4 inhibitors. Diabetes Obes Metab. 2007;9(Suppl. 1):23-31.

4. Amori RE, Lau J, Pittas AG. Efficacy and safety of incretin therapy in type 2 diabetes: systematic review and meta-analysis. JAMA. 2007;298: 194-206.

5. Nauck M, Frid A, Hermansen K, et al. LEAD-2 Study Group. Efficacy and safety comparison of liraglutide, glimepiride, and placebo, all in combination with metformin, in type 2 diabetes: the LEAD (liraglutide effect and action in diabetes)2 study. Diabetes Care. 2009;32:84-90.

6. Buse JB, Rosenstock J, Sesti G, LEAD-6 Study Group, et al. Liraglutide once a day versus exenatide twice a day for type 2 diabetes: a 26-week randomised, parallel-group, multinational, open-label trial (LEAD-6). Lancet. 2009;374:39-47.

7. Buse JB, Drucker DJ, Taylor KL, DURATION-1 Study Group, et al. DURATION-1: exenatide once weekly produces sustained glycemic control and weight loss over 52 weeks. Diabetes Care. 2010;33: 1255-61.

8. Bergenstal RM, Wysham C, Macconell L, DURATION-2 Study Group, et al. Efficacy and safety of exenatide once weekly versus sitagliptin or pioglitazone as an adjunct to metformin for treatment of type 2 diabetes (DURATION-2): a randomised trial. Lancet. 2010;376:431-9.

9. Charbonnel B, Karasik A, Liu J, Wu M, Meininger G. Efficacy and safety of the dipeptidyl peptidase-4 inhibitor sitagliptin added to ongoing metformin therapy in patients with type 2 diabetes inadequately controlled with metformin alone. Diabetes Care. 2006;29:2638-43. 
10. Raz I, Chen Y, Wu M, et al. Efficacy and safety of sitagliptin added to ongoing metformin therapy in patients with type 2 diabetes. Curr Med Res Opin. 2008;24:537-50.

11. Taskinen MR, Rosenstock J, Tamminen I, et al. Safety and efficacy of linagliptin as add-on therapy to metformin in patients with type 2 diabetes: a randomized, double-blind, placebo-controlled study. Diabetes Obes Metab. 2011;13:65-74.

12. Kapitza C, Heise T, Birman P, Jallet K, Ramis J, Balena R. Pharmacokinetic and pharmacodynamic properties of taspoglutide, a once-weekly, human GLP-1 analogue, after single-dose administration in patients with type 2 diabetes. Diabet Med. 2009; 26:1156-64.

13. Nauck MA, Ratner RE, Kapitza C, Berria R, Boldrin $\mathrm{M}$, Balena R. Treatment with the human onceweekly glucagon-like peptide- 1 analog taspoglutide in combination with metformin improves glycemic control and lowers body weight in patients with type 2 diabetes inadequately controlled with metformin alone: a double-blind placebocontrolled study. Diabetes Care. 2009;32:1237-43.

14. Ratner R, Nauck M, Kapitza C, Asnaghi V, Boldrin M, Balena R. Safety and tolerability of high doses of taspoglutide, a once-weekly human GLP-1 analogue, in diabetic patients treated with metformin: a randomized double-blind placebocontrolled study. Diabetic Med. 2010;27:556-62.

15. Pratley RE, Nauck M, Bailey T, 1860-LIRA-DPP-4 Study Group, et al. Liraglutide versus sitagliptin for patients with type 2 diabetes who did not have adequate glycaemic control with metformin: a 26-week, randomised, parallel-group, open-label trial. Lancet. 2010;375:1447-56.

16. DeFronzo RA, Ratner RE, Han J, Kim DD, Fineman MS, Baron AD. Effects of exenatide (exendin-4) on glycemic control and weight over 30 weeks in metformin-treated patients with type 2 diabetes. Diabetes Care. 2005;28:1092-100.
17. Diamant M, Van Gaal L, Stranks S, et al. Once weekly exenatide compared with insulin glargine titrated to target in patients with type 2 diabetes (DURATION-3): an open-label randomised trial. Lancet. 2010;375:2234-43.

18. Drucker DJ, Buse JB, Taylor K, DURATION-1 Study Group, et al. Exenatide once weekly versus twice daily for the treatment of type 2 diabetes: a randomised, open-label, non-inferiority study. Lancet. 2008;372:1240-50.

19. Aroda VR, Ratner R. The safety and tolerability of GLP-1 receptor agonists in the treatment of type 2 diabetes: a review. Diabetes Metab Res Rev. 2011;27:528-42.

20. Fineman MS, Mace KF, Diamant M, et al. Clinical relevance of anti-exenatide antibodies: safety, efficacy and cross-reactivity with long-term treatment. Diabetes Obes Metab. 2012;14:546-54.

21. Marre M, Shaw J, Brandle M, LEAD-1 SU Study Group, et al. Liraglutide, a once-daily human GLP-1 analogue, added to a sulphonylurea over 26 weeks produces greater improvements in glycaemic and weight control compared with adding rosiglitazone or placebo in subjects with Type 2 diabetes (LEAD-1 SU). Diabet Med. 2009;26:268-78.

22. Zinman B, Gerich J, Buse JB, LEAD-4 Study Investigators, et al. Efficacy and safety of the human glucagon-like peptide-1 analog liraglutide in combination with metformin and thiazolidinedione in patients with type 2 diabetes (LEAD-4 Met + TZD). Diabetes Care. 2009;32: 1224-30.

23. Kim D, MacConell L, Zhuang D, et al. Effects of once-weekly dosing of a long-acting release formulation of exenatide on glucose control and body weight in subjects with type 2 diabetes. Diabetes Care. 2007;30:1487-93. 